\title{
COVID-19 in Sri Lanka and Work Setting Changes
}

\author{
Anuruddika K. K. R. Jayathilaka \\ University of Sri Jayewardenepura, Gangodawila, Nugegoda, Sri Lanka \\ Email: anuruddikadec26@gmail.com
}

How to cite this paper: Jayathilaka, A.K.K.R. (2021) COVID-19 in Sri Lanka and Work Setting Changes. Open Access Library Journal, 8: e7008.

https://doi.org/10.4236/oalib.1107008

Received: November 16, 2020

Accepted: January 26, 2021

Published: January 29, 2021

Copyright $\odot 2021$ by author(s) and Open Access Library Inc.

This work is licensed under the Creative Commons Attribution International License (CC BY 4.0).

http://creativecommons.org/licenses/by/4.0/

\section{(c) (i) Open Access}

\begin{abstract}
COVID-19 has made the world to rethink on their work life. With the increasing infected people and death rate, it is vital to rethink about the work setting where people are gathered in big numbers. The study on "COVID-19 in Sri Lanka and Work Setting Changes" is a comprehensive literature survey which was conducted by incorporating desk research strategy in addition to the rational thinking of the author and observations. Throughout the study COVID-19 and the workplace preparedness for COVID-19 in the world and Sri Lanka was addressed. Reasonably believing that this study contributed to existing literature, the author wishes to state the limitations faced and few recommendations for further researches.
\end{abstract}

\section{Subject Areas}

General Management

\section{Keywords}

COVID-19, Sri Lanka, Work Setting, Business, Organization

\section{Introduction}

\subsection{Background of the Study}

On 31 December 2019, the WHO Country Office for China was informed about cases of pneumonia of unknown cause in Wuhan, China (WHO, 2020) [1]. Authorities identified a new type of coronavirus, subsequently named COVID-19 (WHO, 2020) [1]. On 30 January 2020, WHO Director-General declared the outbreak of COVID-19 a Public Health Emergency of International Concern (PHEIC), and on 11 March 2020, COVID-19 was characterized as a pandemic (WHO, 2020) [1]. The Ministry of Health and Indigenous Medical Services in 
collaboration with the WHO Country Office for Sri Lanka continued to closely monitor the situation and to strengthen preparedness and response efforts (WHO, 2020) [1]. Even though an effective and efficient combat is carried out by the key partners in Sri Lanka, still the threat is not over yet. In order to thrive in this situation, the attitudes and practices should be adjusted accordingly by promoting cleanliness.

\subsection{The Research Problem/Research Question}

"How COVID-19 pandemic has impacted the work setting of business organizations in Sri Lanka?" is the research question that the author is focusing on throughout the research study. The research study aims: firstly, to explore how COVID-19 has impacted Sri Lanka; secondly, yet most importantly, to present and describe what work setting changes adopted by an organization under COVID-19 pandemic situation.

\section{Methodology}

In order to achieve the above-mentioned research objectives of the study, a comprehensive literature survey was conducted incorporating desk research strategy in addition to the rational thinking of the author and observations. The author has chosen the review duration over a period of eleven months, starting from January 2020 to November 2020 as the time horizon. The main reason for this selection is that the pneumonia of unknown cause in Wuhan, China was identified on 31 December 2019. A countless of literature related to theory and practices of COVID-19 is available in various publications and conferences. The author searched for the articles related to COVID-19 using the search criteria.

\section{Literature Review}

\subsection{COVID-19}

An outbreak of pneumonia of unknown reason was reported on 31st December 2019 from Wuhan City in Hubei Province of China (Epidemiology Unit, 2020) [2]. On 7th Jan 2020, it was diagnosed as "Novel Corona Virus". On 30/01, WHO has declared it as a Public Health Emergency of International Concern (PHEIC) (Epidemiology Unit, 2020) [2]. On 11/02/2020 the WHO renamed the disease as COVID-19 and on 11/03/2020 declared as pandemic. The incubation period is reported as 2 - 14 days (Epidemiology Unit, 2020) [3]. As of 1 November, nearly 46 million cases and 1.2 million deaths have been reported globally (WHO, 2020) [4]. The further acceleration in the incidence of new cases was most notable in European Region, which reported half of global new cases (over 1.7 million cases, a $22 \%$ increase from the previous week (WHO, 2020) [4]. Moreover, the region also reported a substantial rise in the number of new deaths (a 46\% increase compared with the previous week), with Europe and the Americas now each reporting over 17,000 new deaths in the last 7 days) The Americas and the Eastern-Mediterranean Regions have also seen relatively 
smaller rises in the number of reported cases (WHO, 2020) [4]. The South-East Asia Region has continued to report a decline in new cases and deaths, while case incidence continues to fluctuate around similar rates compared to recent weeks in the African and Western Pacific Regions (WHO, 2020) [4]. Despite regional variations, the countries reporting the highest number of cases in the past week remain the same as in the previous four weeks: The United States of America, India and France (WHO, 2020) [4]. Since the start of the pandemic, nine countries have reported more than 1 million confirmed cases: The United States, India, Brazil, Russian Federation, France, Spain, Argentina, Colombia, and the United Kingdom (WHO, 2020) [4]. Five have reported over 40,000 cumulative deaths: The United States, Brazil, India, Mexico, and the United Kingdom (WHO, 2020) [4].

Sri Lanka is facing a current viral pandemic of Coronavirus COVID-19 as of 10th April 2020, 190 confirmed cases have been reported in the country (Silva, 2020) [5]. On 3rd March 2020, as the first reported case involving a Sri Lankan origin outside Sri Lanka was reported in Italy, nearly 45 quarantine centers have been built in the country by the Sri Lanka Army as a preventive measure to tackle the coronavirus pandemic (Silva, 2020) [5]. Nearly 4000 people have been under quarantine in 45 quarantine centers which also include 31 foreigners from 14 countries (Silva, 2020) [5]. As of $26^{\text {th }}$ March 2020, Sri Lankan authorities have tracked down over 14,000 people who had contacted the identified patients and had ordered be self-quarantined for such people (Silva, 2020) [5]. Following the first reported case of Coronavirus COVID-19 in Sri Lanka on 27 January, demand for face masks in the country soared and the country began to face a severe mask shortage (Silva, 2020) [5].

\subsection{Workplace Preparedness for COVID-19 in World}

The primary way that COVID-19 spreads is through respiratory droplets or contact with contaminated surfaces (Agrawal, Bhardwaj, \& Rajneesh, 2020) [6]. Exposure can occur at the workplace, while travelling to work, during work-related travel to an area with local community transmission, as well as on the way to and from the workplace (WHO, 2020) [1]. There is a likelihood to have a risk of exposure to COVID-19 in the workplace depending on coming within one meter of others, in having frequent physical contact with people who may be infected with COVID-19, and through contact with contaminated surfaces and objects (WHO, 2020) [7]. According to the World Health Organization (2020), the managers with the support of an occupational health and safety advisor should carry out risk assessments to determine the possibility of exposure risk in order to put in place preventive measures. Three types of risk levels have been identifying namely, low exposure risk, medium exposure risk and high exposure risk (Heinzerling, et al., 2020) [8]. Workers who are having low exposure risk have minimal occupational contact with the public and other co-workers (WHO, 2020) [9]. Medium exposure risk level may apply to workers 
who have frequent and close contact with the people in high-population-density work environments (e.g. food markets, bus stations, public transport, and other work activities where physical distancing of at least one meter may be difficult to observe), or tasks that require close and frequent contact between co-workers (WHO, 2020) [9]. Jobs or tasks with close contact with people who may be more likely to have COVID-19, as well as contact with objects and surfaces possibly contaminated with the virus are in the level of high exposure risk (WHO, 2020) [9]. For each risk assessment, consider the environment, the task, the threat, resources available, such as personal protective equipment, and the feasibility of protective measures (WHO, 2020) [9].

Measures to prevent transmission of COVID-19 that apply to all workplaces and all people at the workplace include frequent hand-washing or disinfection with alcohol based hand sanitizer, respiratory hygiene such as covering coughs, physical distancing of at least one meter or more according to the national recommendations, wearing of masks where distancing is not possible, regular environmental cleaning and disinfection, and limiting unnecessary travel (WHO, 2020) [9]. Clear policies and messages, training, and education for staff and managers to increase awareness of COVID-19 are essential while management of people with COVID-19 or their contacts is also critical e.g. requiring workers who are unwell or who develop symptoms to stay at home, self-isolate and contact a medical professional or the local COVID-19 information line for advice on testing and referral (WHO, 2020) [9].

The major responsibility in preventing and control plus mitigating the risk is within the hands of both the employers and employees. Employers, workers, and their organizations should collaborate with health authorities to prevent and control COVID-19 (WHO, 2020) [9]. Cooperation between management and workers and their representatives is essential for workplace-related prevention measures (WHO, 2020) [9]. It is also suggested by World Health Organization, (2020), that the employers should plan and implement measures to prevent and mitigate COVID-19 at the workplace through engineering and administrative controls, and provide personal protective equipment and clothing according to the risk assessment whilst such measures should not involve any expenditure on the part of the workers. It is also concluded by Mayo Clinic, (2020) that several groups are experiencing stigma associated with Covid-19 including, people of Asian descent, people returning from travel, health care workers, people with the disease and their family and friends and people released from quarantine (Feroz, Sultan, \& Feroz, 2020) [10]. Amongst all, people who tested positive for COVID-19, have recovered from being sick with COVID-19, or were released from COVID-19 quarantine are the most obvious victims (Feroz, Sultan, \& Feroz, 2020) [10]. But there should be no social stigma or discrimination at the workplace for any reason, including access to information and protection from COVID-19, occupational health services and mental health and psychosocial support (WHO, 2020) [9]. Nevertheless, workers are responsible to follow the 
measures for occupational safety and health and infection prevention and control established for their workplace, and to participate in training provided by the employer (WHO, 2020) [9]. Workers should report to their supervisor any situation which may present an imminent and serious danger to their life or health as well they have the right to remove themselves from any work situation that they have reasonable justification to believe presents an imminent and serious danger to their life or health, and should be protected from any undue consequences as a result of exercising this right (WHO, 2020) [9]

\subsection{Workplace Preparedness for COVID-19 in Sri Lanka}

It is crucial to remain vigilant as Sri Lanka has recently reported cases of COVID 19 (Epidemiology Unit, 2020) [3]. It is also crucial to understand that businesses and employers in Sri Lanka have a major role to play in order to keep workplaces safe from spread of this disease, COVID-19, as workplaces are frequented by a large number of people. According to the government regulations introduced, in order to reduce the spread of infections, the following measures can be highlighted.

First is being aware of how the COVID-19 spreads. Since this virus can be transmitted from person to person (when they are within a proximity of about 1 $\mathrm{m})$ when someone breathes in droplets coughed or exhaled by persons infected with the virus (Epidemiology Unit, 2020) [3]. Further, when an infected person coughs or exhales, droplets of infected fluid may get released and contaminate nearby surfaces and objects, such as desks, tables or telephones and an uninfected person may contract the virus by touching these surfaces and then touching their eyes, nose or mouth (Epidemiology Unit, 2020) [3]. The second practice is to be aware of who is more at risk. As most persons infected with the virus develop mild symptoms and recover without any complications, those with reduced immunity and people suffering from conditions such as diabetes, heart, kidney, lung and cancer diseases are more at risk (Epidemiology Unit, 2020) [3]. Promote good hand hygiene among employees and customers is the next but most important practice according to my point of view. This is where the attitude has been changed. In this means hand hygiene includes either cleaning hands with soap and water or with an alcohol-based hand rub. The rules imposed under this are making it mandatory to clean their hands before entering the workplace by employees and customers, making hand washing facilities or sanitizing hand rub dispensers available to employees and customers to clean their hands at the main entrances as well as suitable other places, ensuring the hand rub dispensers are regularly refilled and soap and water are freely available at all time, the correct hand washing technique can be demonstrated by posters, leaflets, via LCD panels and, dissemination of information at meetings (Epidemiology Unit, 2020) [3]. Accordingly, all these practices are suggested by the Epidemiology Unit in Sri Lanka in order to kill the virus and prevent the spread of COVID-19. 
Also, by ensuring the cleanliness and hygiene of the workplace the spread of COVID-19 virus can be minimized. There are several ways suggested by the government of Sri Lanka to practice. Paying attention to regular disinfection of surfaces (e.g. desks and tables) and objects (e.g. shared used telephones, keyboards, teller machines, door handles and railings etc.) with a suitable disinfectant several times a day is one way to ensure workplace hygiene. Also keeping the doors open as much as possible (e.g. non-air conditioned areas) is a suggested way by Epidemiology Unit (2020) in order to minimize the necessity to touch the door handles. Where air-conditioned opening the doors using body is recommended as this will minimize the contact of door handles, places, where you have to pull to open. To be more effective it is advisable to use a disposable tissue for the door handle and immediately discard it. As well in order to minimize the overcrowding of customers (supermarkets, shops, banks, government offices, etc.) inside the workplace, keeping at least one meter gap between the customers and the officers who have direct customer relationships and if this is not possible, it is advised to wear a face mask by such officers while on duty, wash their hands more often than others and should not touch their face with unwashed hands are the few rules imposed (Epidemiology Unit, 2020) [3]. This is also vital because touching surfaces contaminated with infectious material is one of the main ways that COVID-19 spreads (Chia, et al., 2020) [11]. Another practice that is proposed is to keep surgical masks and/or paper tissues at the workplace for use by those who develop a runny nose or cough at work, along with closed bins for their hygienic disposal (Epidemiology Unit, 2020) [3]. This is also preventing the spread of COVID-19. It is equally important to ensure access to Information, thus it is recommended to take steps to display posters promoting hand washing and respiratory hygiene by the employers (Epidemiology Unit, 2020) [3]. Furthermore, information can be shared through intranet or at meetings and necessary information to be shared can be obtained from the websites of health authorities (http://www.epid.gov.lk/) (Epidemiology Unit, 2020) [3]. It is advised to brief employees to stay at home if anyone experiences a mild cough or low-grade fever (37.3 C or more) (Epidemiology Unit, 2020) [3].

The government has also instructed the organizations to be updated on areas where COVID 19 is currently spreading before travelling abroad. This information can be accessed at, https://www.who.int/emergencies/diseases/novel-coronavirus-2019. Also, the personnel is acclaimed to be educated in order to assess the benefits and risks related to plan international travel based on this latest update (Epidemiology Unit, 2020) [3]. Epidemiology Unit, Ministry of Health \& Indigenous Medical Services, (2020) always request the management that international travel to areas where COVID-19 is spreading should be avoided for employees at higher risk of serious illness (e.g. older employees and those with medical conditions such as diabetes, heart and lung disease). Also, it is counseled to advise employees who have returned from an area where COVID-19 is spreading to monitor them- 
selves for symptoms for 14 days and take their temperature twice a day also if they develop even a mild cough or low-grade fever (i.e. a temperature of $37.3 \mathrm{C}$ or more) instruct to seek care at the nearest government hospital immediately (Epidemiology Unit, 2020) [3]. Another aspect is to manage COVID-19 risk when organizing meetings \& events. Before the meeting or event, consider whether a face-to-face meeting or event is needed and whether it could be replaced by a Teleconference or online event (Epidemiology Unit, 2020) [3]. If a meeting is essential to be held, minimize the number of attendees, do not shake hands with other participants, instead say "Ayubowan", pre-order sufficient supplies and materials, including tissues and hand sanitizer for all participants, maintain a distance of $1 \mathrm{~m}$ between participants, and follow all the hygienic measures outlined above (Epidemiology Unit, 2020) [3].

\section{Discussion}

Getting in line with the global and local practices introduced, businesses have been able to move forward. Five workforce areas are emerging as priorities for business leaders. First is protecting people via initiating measures to help support employees' physical and emotional well-being, whether at work or at home (PwC Global, 2020) [12]. Second is communicating effectively in global uncertainty by leading with responsive, empathetic communications and policies that help people feel informed and supported (PwC Global, 2020) [12]. Also another is maintaining the continuity of work along with providing the resources and support employees need to be productive, especially as they adapt to working remotely (PwC Global, 2020) [12]. Nevertheless assessing workforce costs is another emerging priority where exploring workforce levers to help balance the potential need to cut costs with the desire to keep people employed is involved (PwC Global, 2020) [12]. Finally, preparing for recovery through aligning workforce planning with the business strategy and prepare for an evolving market in order, to ramp up in a recovery (PwC Global, 2020) [12]. The paper has already discussed some of the literature about the work setting changes proposed. This section gives a quick glimpse of few papers that have pointed out the implementation of the changes proposed in practice in terms of four major sectors in economy.

With regard to the health care sector twelve quarantine detail centers, four testing centers and thirty-one government hospital which are especially devoted to treat corona virus infected were specially established. Health care staff will be subjected to both physical and psychological stress when involved in patient care during a pandemic of such magnitude (Ministry of Health, 2020) [13]. Therefore, early measures to address burnout would ensure better service provision during this difficult period and ensure safety of health care providers by providing special guidelines to be practiced (Ministry of Health, 2020) [13]. Also when staffing doctors, nurses and ICU staff a mandatory requirement is announced that the staff should be on a roster ensuring that the minimal number of per- 
sonnel is present at a given time to avoid unnecessary exposure to all concerned (Ministry of Health, 2020) [13].

During the COVID-19 pandemic, more than $90 \%$ of higher education institutions (state and non-state) carried out remote learning (mostly online) (Hayashi, Garcia, Maddawin, \& Hewagamage, 2020) [14]. Online education enabled continuous learning without spreading COVID-19, saved time and physical space in delivering course content, facilitated information sharing and on-demand learning, and provided flexibility in teaching delivery (Hayashi, Garcia, Maddawin, \& Hewagamage, 2020) [14]. This is how the educational sector in Sri Lanka has changed their settings. Two most important examinations were held under these circumstances. Grade 5 scholarship exam and Advance Level examination were held under strict health regulations across the island (Ratnayake, 2020) [15]. The students receiving treatment at the National Institute of Infectious Diseases (IDH) sat for the exam at the hospital premises while the others followed all the practices, rules and regulations imposed (Xinhua, 2020) [16].

Given the importance of the tourism sector to the national economy of Sri Lanka, it is paramount that tourism activities resume at the earliest, by ensuring all necessary health and safety protocols and procedures are in place (SLTDA, 2020) [17]. The protocols which introduced are presented under few captions starting from the entry procedure to the country to departure at the airport. Apart from the general information the changes to be implemented, several practices were suggested by Sri Lanka Tourism Development Authority (SLTDA) are as follows. It is recommended that all staff (Executive and non-executive) should undergo random PCR () tests and relevant records should be maintained for verification by the SLTDA; staff should also wear face masks when reporting for duty and should enter the premises through one common entrance (SLTDA, 2020) [17]. Day staff reporting for duty should not carry any additional clothing with them. Resident staff should carry minimum amount of clothing when coming into the facility; any baggage brought in by staff should be disinfected at the gate before being permitted in (SLTDA, 2020) [17]. It is also made sure to maintain hygiene and cleanliness by making it compulsory to do laundry daily and use the fresh cloths after taking a bath by the employees (SLTDA, 2020) [17]. The sharing of mobile phones, pens, pencils, food/beverage items, cigarettes, personal grooming items, etc. among staff should be totally avoided as well games such as carom, chess, etc. are not allowed in the staff recreation rooms due to the difficulty in maintaining the safe physical distancing requirements (SLTDA, 2020) [17].

As an essential service provider banks are committed to supporting the facilitation of economic activity and money circulation and many of the branches have remained open to the public, with adequate measures being implemented to ensure the safety of employees and customers (BOC, 2020) [18]. Necessary measures have been taken to enable staff of non-critical areas to work from home while stringent checks are in place for front-line staff that is inevitably exposed to outside parties (BOC, 2020) [18]. Many measures are also taken to en- 
sure the safety of the customers who visit the Bank branches and ATMs (BOC, 2020) [18]. The banks are also cognizant of the role they have to play in ensuring the continued functioning of the country's payment and settlement systems and facilitate cash circulation among masses; accordingly, in line with Government guidelines, all efforts have been made to continuously offer essential services, albeit in a limited manner across all districts in the country (BOC, 2020) [18].

But twist has been recorded in recent past in Sri Lanka, in the incidents of Minuwangoda garment workers and Peliyagoda fish market. Colombo (AsiaNews) reports that workers employed in the garment industry are being blamed for the spread of COVID-19 and the quarantine imposed on them is a form of punishment, trade unions said at a recent meeting held at the Centre for Society and Religion (CSR) in Colombo (Perera M. M., 2020) [19]. They accuse the authorities of discriminating against segments of the population in their efforts to contain the pandemic; instead, they should go and see how garment workers are forced to live this crisis situation (Perera M. M., 2020) [19]. At present, the garment plant in Minuwangoda, one of the largest local apparel manufacturers, is the main cluster (Perera M. M., 2020) [19]. The Peliyagoda fish market coronavirus cluster believed to have been triggered by the fresh eruption of the contagion at Minuwangoda appears to be quite big in dimension and widespread in its reach, a senior medical official said (Perera S., 2020) [20]. It is believed to have passed on the infection to the others working within the complex, though it has still not been established how he picked up the virus (Perera S., 2020) [20]. Therefore, it is doubtful whether all the organizations are adhering to Workplace Preparedness which was established by the local global health authorities.

\section{Conclusion}

Even though many researches have been conducted on the impact of COVID-19, there is a lack of concentrating on the Sri Lankan context. Therefore, I hope this study will contribute to the existing literature relating to COVID-19. Further, it will be a guide for the employers to adhere to the practices introduced by the organizations related to health and safety. Since this was conducted incorporating desk research strategy, I believe another researcher can attempt to the same in a more practicable manner by living in the field. Even though I make an attempt to follow the rules and write down to output a coherent article, I feel the lack of industrial knowledge regarding the same phenomena that this research study is all about.

\section{Conflicts of Interest}

The author declares no conflicts of interest regarding the publication of this paper.

\section{References}

[1] WHO (2020) Coronavirus Disease (COVID-19): Health and Safety in the Workplace. 
https://www.who.int/news-room/q-a-detail/q-a-tips-for-health-and-safety-at-the-w orkplace-in-the-context-of-covid-19?gclid=Cj0KCQiA7qP9BRCLARIsABDaZzhyPj 7K6MLdZ7zcF1 x1CeJyiflkdQlT7AP-Hfd wxwJUe4B72L3eMaAufhEALw wcB

[2] Epidemiology Unit (2020) Guidance for Workplace Preparedness for COVID-19. Epidemiology Unit, Ministry of Health \& Indigenous Medical Services.

[3] Epidemiology Unit (2020) Coronavirus Disease 2019 (COVID-19) Situation Report. Ministry of Health, Sri Lanka.

[4] WHO (2020) Sri Lanka-Covid 19. https://www.who.int/srilanka/covid-19

[5] Silva, S. (2020) Sri Lanka: Victory against the COVID 19: Get Ready for Hardworking to Make the Country Better. D.A.C.

[6] Agrawal, A. and Bhardwaj, R. (2020) Tailoring Surface Wettability to Reduce Chances of Infection of COVID-19 by a Respiratory Droplet and to Improve the Effectiveness of Personal Protection Equipment. Physics of Fluids, 32, Article ID: 081702. https://doi.org/10.1063/5.0020249

[7] WHO (2020) COVID-19 Weekly Epidemiological Update. World Health Organization, Geneva.

[8] Heinzerling, A., Stuckey, P.M., Scheuer, T., Xu, K., Perkins, K., Resseger, H., et al. (2020) Transmission of COVID-19 to Health Care Personnel during Exposures to a Hospitalized Patient-Solano County, California, February 2020. Morbidity and Mortality Weekly Report (MMWR), 69, 472-476.

https://doi.org/10.15585/mmwr.mm6915e5

[9] WHO (2020) Rational Use of Personal Protective Equipment (PPE) for Coronavirus Disease (COVID-19): Interim Guidance, 19 March 2020. World Health Organization, Geneva.

[10] Feroz, A.S., Sultan, S. and Feroz, R. (2020) Reducing Stigma and Discrimination around Covid-19 Outbreak. Pakistan Journal of Public Health, 10, 1.

[11] Chia, P.Y., Coleman, K.K., Tan, Y.K., Ong, S.W., Gum, M., Lau, S.K., et al. (2020) Detection of Air and Surface Contamination by Severe Acute Respiratory Syndrome Coronavirus 2 (SARS-CoV-2) in Hospital Rooms of Infected Patients. https://doi.org/10.1101/2020.03.29.20046557

[12] PwC Global (2020) COVID-19: Impacts to Business. https://www.pwc.com/gx/en/issues/crisis-solutions/covid-19.html

[13] Ministry of Health (2020) Provisional Guidelines for Clinical Management of COVID-19. Ministry of Health, Sri Lanka.

[14] Hayashi, R., Garcia, M., Maddawin, A. and Hewagamage, K.P. (2020) Online Learning in Sri Lanka's Higher Education Institutions during the COVID-19 Pandemic. ADB Briefs. https://doi.org/10.22617/BRF200260-2

[15] Ratnayake, J. (2020) Grade 5 Scholarship Exam Held amidst Strict Health Regulations. https://www.newsfirst.lk https://www.newsfirst.lk/2020/10/11/grade-5-scholarship-exam-held-amidst-stricthealth-regulations

[16] Xinhua (2020) Sri Lanka Holds Exams amid New COVID-19 Cluster. http://www.xinhuanet.com http://www.xinhuanet.com/english/2020-10/12/c 139435183.htm

[17] SLTDA (2020) Sri Lanka Tourism Operational Guidelines with Health Protocols. Sri Lanka Tourism Development Authority, Sri Lanka.

[18] BOC (2020) Annual Report 2019. Bank of Ceylon, Sri Lanka.

[19] Perera, M.M. (2020) Minuwangoda Garment Workers Blamed for the Spread of 
COVID-19.

http://www.asianews.it/news-en/Minuwangoda-garment-workers-blamed-for-the-s pread-of-COVID-19-51344.html

[20] Perera, S. (2020) Peliyagoda Fish Market Cluster Big and Widespread in Its Reach. https://island.lk/peliyagoda-fish-market-cluster-big-and-widespread-in-its-reach 